\title{
Letter to the Editor on "How to Become a Competitive Applicant for Gastroenterology Fellowship: Tips and Tricks for Success Part II"
}

\author{
Michelle Guo ${ }^{1,7}\left[\right.$ Amy S. Oxentenko ${ }^{2} \cdot$ Sogol Mostoufi-Moab ${ }^{1,3} \cdot$ Rachel N. Pham $^{4} \cdot$ Priscila R. Armijo ${ }^{5}$. \\ Julie K. Silver ${ }^{6}$
}

Received: 22 July 2020 / Accepted: 21 August 2020 / Published online: 5 September 2020

(c) Springer Science+Business Media, LLC, part of Springer Nature 2020

\section{Dear Editor,}

We read with interest the recent article "How to Become a Competitive Applicant for Gastroenterology Fellowship: Tips and Tricks for Success Part II" by Duong, Aby, Hathorn, Simons-Linares, and Bilal [1]. As the second part of a two-part series tailored to trainees pursuing a career in gastroenterology (GI), this article highlights strategies for applicants to craft a strong application and offers additional considerations for women and minorities. We applaud the authors for highlighting the unique circumstances faced by women and the importance of support infrastructure for diversity and inclusion. Approaching this issue from the trainee perspective, Duong et al. recommend that applicants consider the demographics of leadership to gain insight into the institution's commitment to diversity. We are writing with a recommendation directed at program directors, faculty interviewers, and other leaders: Prioritize the recruitment of women in training, including women with intersectional identities (e.g., racial/ethnic minorities, women with disabilities, sex/gender minorities) into GI fellowship programs.

Michelle Guo

michelle.guo@pennmedicine.upenn.edu

Amy S. Oxentenko

oxentenko.amy@mayo.edu

Sogol Mostoufi-Moab

moab@email.chop.edu

Rachel N. Pham

rachelpham@creighton.edu

Priscila R. Armijo

p.rodriguesarmijo@unmc.edu

Julie K. Silver

julie_silver@hms.harvard.edu

1 Perelman School of Medicine, University of Pennsylvania, Philadelphia, PA, USA
Although the onus to fix gaps should be firmly placed on leaders in academic medicine, we recognize that there are genuine barriers to recruitment, such as inherent sex/gender bias and lack of mentoring. Approximately $40 \%$ of third-year internal medicine residents are female, and the percentage of female first-year GI fellows has remained stable between 32 and $39 \%[2,3]$. However, less than $20 \%$ of practicing gastroenterologists are female (Fig. 1) [4]. Singh et al. showed that female gastroenterologists were more frequently in academic practice than male (38\% vs $17 \%$ ) but were less likely to hold the most advanced academic positions [5]. More recently, Diamond et al. showed that in a cohort of 2440 GI faculty members, only $11 \%$ of women hold the rank of professor compared with $30 \%$ of men [6]. Paving a future for women in gastroenterology means systematically evaluating barriers for women achieving leadership roles within the specialty.

With the unique challenges posed by the COVID-19 pandemic during this application season, programs must demonstrate their dedication to diversity through virtual forums. Mallepally et al. suggest solutions for GI fellowship programs, including strengthening their online or social media presence [7]. Already facing a highly competitive fellowship

2 Division of Gastroenterology and Hepatology, Department of Medicine, Mayo Clinic College of Medicine and Science, Mayo Clinic, Phoenix, AZ, USA

3 Divisions of Endocrinology and Oncology, The Children's Hospital of Philadelphia, Philadelphia, PA, USA

4 Creighton University School of Medicine, Omaha, NE, USA

5 Department of Surgery, University of Nebraska Medical Center, Omaha, NE, USA

6 Department of Physical Medicine and Rehabilitation, Harvard Medical School, Massachusetts General Hospital, Brigham and Women's Hospital, Spaulding Rehabilitation Hospital, Boston, MA, USA

7 Jordan Medical Education Center, 6th Floor, 3400 Civic Center Blvd, Building 421, Philadelphia, PA 19104-5162, USA 


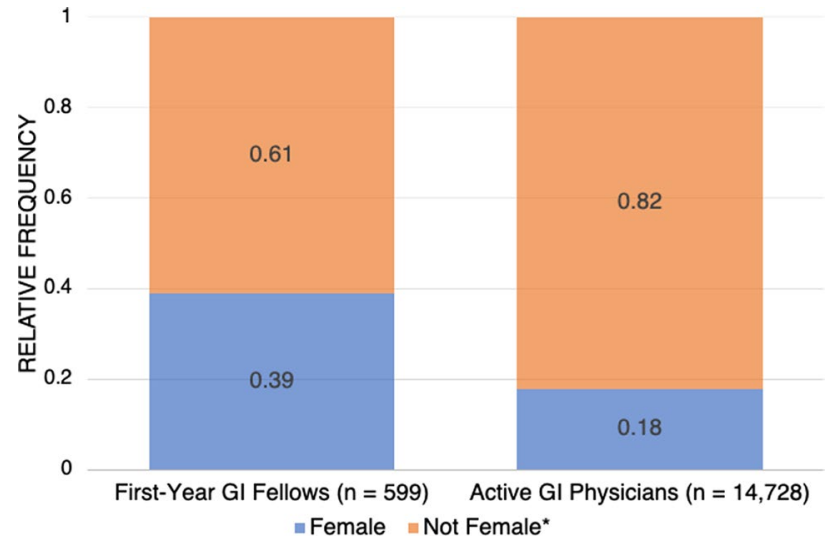

Fig. 1 Relative frequency of first-year GI fellows and active GI physicians stratified by sex. Frequencies are within fellows and physicians. Data from American Board of Internal Medicine (2018) and Association of American Medical Colleges (2017) [3, 4]. *Note the ABIM provides data for female first-year fellows but does not give a value for male first-year fellows. Thus, the term "not female" is used here

match, women applicants and those with intersectional identities may analyze fellowship websites for the names and faces of leaders who share those identities. Programs must be prepared to be transparent and carefully consider how they present their culture and values.

Closing gaps in the recruitment of women into any specialty is the responsibility of program directors, department chairs, and other institutional leaders. Duong et al. provide practical guidelines that are applicable across a variety of specialties. Equally important are the recommendations for ensuring that women physicians have a chance to be considered for and ultimately appointed as leaders of their departments. Without this consistency in institutional priority, women will compete for the few spots available at institutions where structured support for diversity and inclusion exists and is readily apparent. Now is the time to demonstrate to the medical profession that diversity and inclusion is a priority, and to put efforts behind statements of solidarity.
Funding No funding was received for this work.

\section{Compliance with Ethical Standards}

Conflict of interest Michelle Guo, BA, has no disclosures related to this work; Amy S. Oxentenko, MD, FACP, FACG, AGAF-no disclosures related to this work; Sogol Mostoufi-Moab, MD, MSCE-no disclosures related to this work; Rachel N. Pham, BS-no disclosures related to this work; Priscila R. Armijo, MD—no disclosures related to this work; and Julie K. Silver, MD—no disclosures related to this work.

\section{References}

1. Duong N, Aby ES, Hathorn KE, Simons-Linares CR, Bilal M. How to become a competitive applicant for gastroenterology fellowship: tips and tricks for success part II. Dig. Dis. Sci. 2020;65:2172-75. https://doi.org/10.1007/s10620-020-06293 $-4$.

2. Percentage of third-year internal medicine residents who are female. https://www.abim.org/about/statistics-data/resident-fello w-workforce-data/third-year-residents-female.aspx. Accessed 7 July 2020.

3. Percentage of first-year fellows by gender and type of medical school attended. https://www.abim.org/about/statistics-data/resid ent-fellow-workforce-data/first-year-fellows-by-gender-type-ofmedical-school-attended.aspx. Accessed 7 July 2020.

4. Active physicians by sex and specialty, 2017. https://www.aamc. org/data-reports/workforce/interactive-data/active-physicians-sexand-specialty-2017. Accessed 7 July 2020.

5. Singh A, Burke CA, Larive B, Sastri SV, Women in Gastroenterology Committee of American College of Gastroenterology. Do gender disparities persist in gastroenterology after 10 years of practice? Am J Gastroenterol. 2008;103:1589-95. https://doi.org /10.1111/j.1572-0241.2008.01976.x.

6. Diamond SJ, Thomas CR, Desai S, et al. Gender differences in publication productivity, academic rank, and career duration among U.S. academic gastroenterology faculty. Acad Med. 2016;91:1158-1163. https://doi.org/10.1097/ACM.0000000000 001219.

7. Mallepally N, Bilal M, Hernandez-Barco YG, Simons M, Berzin TM, Oxentenko AS. The new virtual reality: how COVID-19 will affect the gastroenterology and hepatology fellowship match. Dig Dis Sci. 2020. https://doi.org/10.1007/s10620-020-06432-x.

Publisher's Note Springer Nature remains neutral with regard to jurisdictional claims in published maps and institutional affiliations. 